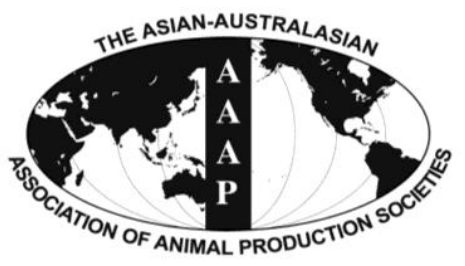

Asian-Aust. J. Anim. Sci.

Vol. 25, No. $8: 1089$ - 1095

August 2012

www.ajas.info

http://dx.doi.org/10.5713/ajas.2012.12017

\title{
Tissues Expression, Polymorphisms Identification of FcRn Gene and Its Relationship with Serum Classical Swine Fever Virus Antibody Level in Pigs
}

\author{
Liu Yanga, Wang Chonglong a , Liu Zhengzhu, Xu Jingen, Fu Weixuan, Wang Wenwen, \\ Ding Xiangdong, Liu Jianfeng and Zhang Qin* \\ Key Laboratory of Animal Genetics, Breeding and Reproduction, Ministry of Agriculture, \\ College of Animal Science and Technology, China Agricultural University, Beijing 100193, China
}

\begin{abstract}
Neonatal $\mathrm{Fc}$ receptor ( $\mathrm{FcRn}$ ) gene encodes a receptor that binds the Fc region of monomeric immunoglobulin $\mathrm{G}$ (IgG) and is responsible for $\mathrm{IgG}$ transport and stabilization. In this report, the $8,900 \mathrm{bp}$ porcine FcRn genomic DNA structure was identified and putative FcRn protein included 356 amino acids. Alignment and phylogenetic analysis of the porcine FcRn amino acid sequences with their homologies of other species showed high identity. Tissues expression of FcRn mRNA was detected by real time quantitative polymerase chain reaction (Q-PCR), the results revealed FcRn expressed widely in ten analyzed tissues. One single nucleotide polymorphism (SNP) (HQ026019:g.8526 C>T) in exon6 region of porcine FcRn gene was demonstrated by DNA sequencing analysis. A further analysis of SNP genotypes associated with serum Classical Swine Fever Virus antibody (anti-CSFV) concentration was performed in three pig populations including Large White, Landrace and Songliao Black pig (a Chinese indigenous breed). Our results of statistical analysis showed that the SNP had a highly significant association with the level of anti-CSFV antibody (At d 20; At d 35) in serum $(\mathrm{p}=0.008 ; \mathrm{p}=0.0001)$. Investigation of expression and polymorphisms of the porcine FcRn gene will help us in further understanding the molecular basis of the antibody regulation pathway in the porcine immune response. All these results indicate that FcRn gene might be regarded as a molecular marker for genetic selection of anti-CSFV antibody level in pig disease resistance breeding programmes. (Key Words: Pig, FcRn, Anti-CSFV, Expression, Polymorphism, Association)
\end{abstract}

\section{INTRODUCTION}

Immunoglobulin $\mathrm{G}(\operatorname{IgG})$ is the most prevalent antibody that has an important role in long-term humoral immunity. It has also been regarded as a pathological effecter of systemic autoimmune diseases such as systemic lupus erythematosus and spontaneous abortion in multiparous females (Roopenian et al., 2003). It has long been known that $\mathrm{IgG}$ is the only class of antibodies that is efficiently transferred from mother to offspring to develop short-term passive immunity in new born animals (Morphis and Gitlin, 1970; Brambell, 1996; Roopenian and Akilesh, 2007). This specific transport of $\mathrm{IgG}$ is dependent on the neonatal $\mathrm{Fc}$ receptor (FcRn) (Simister and Mostov, 1989; Roberts et al., 1990), which was originally identified by Simister and

\footnotetext{
* Corresponding Author: Qin Zhang. Tel: +86-10-62732634, Fax: +86-10-62732634, E-mail: qzhang@ cau.edu.cn

${ }^{a}$ These authors contributed equally to this work.

Submitted Jan. 8, 2012; Accepted Apr. 26, 2012; Revised May 17, 2012
}

Waldmann (Jones and Waldmann, 1972).

FcRn gene functions as the receptor responsible for $\mathrm{IgG}$ binding and shares 22 to $29 \%$ sequence identity with Major Histocompatibility Complex (MHC) Class I molecules (Simister and Mostov, 1989; Raghavan and Bjorkman, 1996). In this process, FcRn binds to the Fc region of IgG in a strictly pH-dependent manner (Brambell, 1966; Praetor et al., 1999) and is then transported through maternally derived IgG from milk across the intestinal epithelial-cell layer of the neonatal rodents. In addition, beyond the perinatal period, FcRn protects $\operatorname{IgG}$ from degradation, thereby prolongs the half-life of IgG antibodies in the serum, this function is key to $\operatorname{IgG}$ homeostasis, that helps this protective class of antibody in maintaining a high concentration in immune circulation (Jones and Waldmann, 1972; McCarthy et al., 2000; Roopenian et al., 2003; Roopenian and Akilesh, 2007).

Since FcRn is the only receptor responsible for perinatal $\mathrm{IgG}$ transport, $\mathrm{FcRn}$ has been regarded as a promising target 
gene for enhancing protective humoral immunity. Due to the important role of $\mathrm{FcRn}$ for $\mathrm{IgG}$ transport and stabilization, genetic variations of FcRn-dependent transport may influence antibody immunity of the newborn. Strong evidence reveals various mutations at different positions of some amino acid residues around the FcRn-Fc binding interface. These improve the $\mathrm{pH}$-dependent binding of human IgG to FcRn (Shields et al., 2001; Hinton et al., 2004; Kamei et al., 2005; Vaccaro et al., 2005; Hinton et al., 2006; Petkova et al., 2006). Therefore, research into the genetic mechanism of FcRn gene seems to be an attractive strategy and may provide reference for modulating specific IgG transport to promote host's disease defense.

Considering its influence on the antibody immune response pathway, FcRn could be an important candidate gene for porcine antibody immune response and disease susceptibility. In this study, we firstly identified the genomic structure of the porcine FcRn gene, detected its expression in different tissues and polymorphisms in the regions of exons, and we also further performed an association analysis between the SNPs of the FcRn gene and anti-CSFV antibody level in serum to estimate their possible effects in three pig populations.

\section{MATERIALS AND METHODS}

\section{Animals and DNA isolation}

Three pig breed populations including Landrace, Large White and a Chinese indigenous breed Songliao Black were collected from the experimental farm of the Institute of Animal Sciences, Chinese Academy of Agricultural Sciences, Beijing, China. 296 pigs were vaccinated with CSF live vaccine at the age of 21 days. The first blood samples were collected from each piglet one day before the vaccination (At d 20), and 2 wks after the vaccination, the second blood samples were collected (At d 35). Ear tissues and blood samples of all pigs were also collected for DNA extraction using phenol/chloroform extraction and ethanol precipitation (Sambrook et al., 1989). Nine different tissues, including heart, liver, spleen, lung, kidney, skeletal muscle, lymph node, brain and thymus, were collected from three 35-d-old Landrace pigs, then immediately frozen in liquid nitrogen and stored at $-80^{\circ} \mathrm{C}$.

\section{Measurement of CSFV antibody IgG level in serum}

Serum samples from three pig populations were stored at $-80^{\circ} \mathrm{C}$. Anti-CSFV IgG level in serum samples were measured using the Herdchek* CSFV Antibody (IgG) ELISA Test Kit (IDEXX Laboratories, America), which contains 96-well test plates coated with CSFV antigen, sample diluent, positive control: standards of known CSFV antibody concentrations, negative control, washing solution, a CSFV antigen and a biotinylated monoclonal antibody specific to CSFV, and a tetramethyl benzidine (TMB) substrate solution. Serum samples from the pig populations and standards of known CSFV concentrations were loaded into the wells on the test plate: $50 \mu$ of each serum sample or standard per well. The CSFV antigen and the biotinylated monoclonal antibody specific to CSFV were added to each well and were incubated at $20^{\circ} \mathrm{C}$ for $120 \mathrm{~min}$. The wells were washed and with then $100 \mu \mathrm{l}$ anti-CSFV horseradish peroxidase (HRPO) conjugate was added. After incubation at room temperature for $30 \mathrm{~min}$, the wells were washed to remove unbound enzymes and the substrate solution, which reacted with the bound enzyme to induce a colour, was added. The intensity of the colour was proportional to the concentration of CSFV IgG present in the serum samples. The intensity of the colour was measured with an ELISA reader at $450 \mathrm{~nm}$ to calculate the mean absorbance values, these values were then converted into CSFV antibody concentration blocking percentage $(\%)$ in serum according to the manufacturer's instructions.

\section{Total RNA extraction and cDNA synthesis}

The total RNA was extracted from ten different tissues (liver, thymus, spleen, lymphoid node, heart, skeletal muscle, kidney, lung, small intestine, and brain) of three 35 days old Landrace pigs with a TRIzol reagent (Invitrogen, USA). In order to prevent serious contamination by genomic DNA, DNaseI (Beijing Tiangen Biotechnology, China) treatment on the total RNA was carried out, and then the first strand cDNA was synthesized in the presence of 2 $\mu \mathrm{g}$ total RNA, $0.5 \mu \mathrm{M}$ oligo(dT)18, $200 \mu \mathrm{M}$ dNTPs, $10 \mathrm{U}$ RNAsin (Promega, Madison, WI, USA), $1 \times$ M-MLV RT buffer, and $300 \mathrm{U}$ M-MLV reverse transcriptase (Promega, USA) in a volume of $50 \mu \mathrm{l}$ at $40^{\circ} \mathrm{C}$ for $1 \mathrm{~h}$.

\section{Real time Q-PCR analysis of FcRn mRNA expression}

The real time quantitative PCR (Q-PCR) method was used to investigate the expression of FcRn gene in ten porcine tissues. A quantitative primer pair which spanned an intron was designed to eliminate potential confounding results from genomic DNA contamination (Table 1). Another primer set was also designed to amplify porcine glyceraldehyde3-phosphate dehydrogenase (GAPDH) mRNA (GenBank accession number: AF017079) as a positive control (F1 5'- TGAGACACGATGGTGAAGGT$3^{\prime}$ and R1 5'-GGCATTGCTGATGATCTTGA-3'). PCR reactions were performed in a final volume of $15 \mu \mathrm{l}$ using DyNAmo $^{\text {TM }}$ SYBR $^{\circledR}$ Green qPCR Kits (Finnzymes, Finland). All reactions were performed in optical tubes (Bio-Rad Laboratories, USA). First, $1 \mu \mathrm{l}$ of template and 1 $\mu \mathrm{l}$ specific primer were delivered into the tubes, followed by $8.0 \mu \mathrm{l}$ of $\mathrm{SYBR}^{\circledR}$ Green Q-PCR master mix and $6.0 \mu \mathrm{l}$ $\mathrm{ddH}_{2} \mathrm{O}$. The tubes were sealed with optical caps (Bio-Rad 
Table 1. Primers used for mRNA expression and SNPs detection of the porcine FcRn gene

\begin{tabular}{|c|c|c|c|c|}
\hline Fragments & Primers sequence $\left(5^{\prime} \sim 3^{\prime}\right)$ & Product size (bp) & PCR (Tm) & Used for \\
\hline FcRn-1 & $\begin{array}{l}\text { AGGTCTCCCGCTCAGGAT } \\
\text { GGATGTTGCTTCCTTTGCTC }\end{array}$ & 200 & 59.7 & SNP identification \\
\hline FcRn-2 & $\begin{array}{l}\text { CTCCСТCСТGTACACCTCA } \\
\text { AGGCCCACCТCCTTCCTC }\end{array}$ & 259 & 60.5 & SNP identification \\
\hline FcRn-3 & $\begin{array}{l}\text { GAATTGGGCCCCGACAAT } \\
\text { CTGCTCACCCTTCCACTCC }\end{array}$ & 252 & 61.0 & SNP identification \\
\hline FcRn-4 & $\begin{array}{l}\text { ATCGCCTTCTCCTTCTACCC } \\
\text { AGAGGGGAAAAAGGCAACC }\end{array}$ & 300 & 59.8 & SNP identification \\
\hline FcRn-5 & $\begin{array}{l}\text { GAGGTTGGGAGGGACTGACT } \\
\text { CСTCTCACGGAGGCACTTC }\end{array}$ & 260 & 60.5 & SNP identification \\
\hline FcRn-6 & $\begin{array}{l}\text { ACCCAGGGGATTTCAAGATT } \\
\text { AAATTGGCAGATTCCACCAT }\end{array}$ & 506 & 60.2 & SNP detection \\
\hline FcRn-Q & $\begin{array}{l}\text { GCTGGGGCATCTGGAGAG } \\
\text { TAGGAAGCCGACCATGATTC }\end{array}$ & 380 & 60.5 & mRNA expression \\
\hline
\end{tabular}

Laboratories, USA). All reactions were performed with a DNA Engine Opticon 2 Real-Time system (MJ Research, USA). The PCR program was optimized and consisted of an enzyme activation step $\left(95^{\circ} \mathrm{C}, 10 \mathrm{~min}\right)$, forty cycles of denaturation $\left(95^{\circ} \mathrm{C}\right.$ for $\left.30 \mathrm{~s}\right)$, annealing extension $\left(60.5^{\circ} \mathrm{C}\right.$, for $30 \mathrm{~s})$, extension $\left(72^{\circ} \mathrm{C}\right.$ for $\left.35 \mathrm{~s}\right)$, reading plate, and incubation $\left(84^{\circ} \mathrm{C}\right.$ for $\left.1 \mathrm{~s}\right)$, followed by an extension at $72^{\circ} \mathrm{C}$ for $10 \mathrm{~min}$. Then, a melting curve from $55^{\circ} \mathrm{C}$ to $95^{\circ} \mathrm{C}$, reading every $0.3^{\circ} \mathrm{C}$ for $1 \mathrm{~s}$, was drawn. All data were analyzed using Opticon Monitor 2.0 software (MJ Research, USA).

\section{Genomic organization and SNPs identification of the porcine FcRn gene}

To characterize the genomic structure of the porcine FcRn gene, the mRNA sequences of the porcine FcRn gene (GenBank accession number: AY135635) was used to search for porcine homologous high throughput genomic sequences (HTGS) in the porcine genomic databases by BLAST (http://blast.ncbi.nlm.nih.gov) of NCBI GenBank database (http://www.ncbi.nlm.nih.gov/). One genomic DNA fragment (GenBank accession number: FP102630.3) was obtained, which contains all introns and exons of the porcine FcRn gene. Furthermore, the genomic organization was also subsequently deduced by experimental confirmation using exon-exon PCR across predicted introns or exon-intron PCR. Finally, the sequence of porcine FcRn genomic DNA was submitted to NCBI GenBank database.

The porcine FcRn gene consists of six exons. Therefore, using porcine genomic DNA, six primer pairs were designed for PCR amplification of DNA sequences including all exon regions of the IRF6 gene (Table 1). The DNA from two pigs from each breed was selected for PCR amplification. All PCR fragments were purified with a Gel Extraction Mini Kit (Beijing Tiangen Biotechnology, China) and then sequenced. After comparing the sequences obtained from the same PCR fragments from two pigs of each of the Landrace, Large White and Songliao Black breeds the polymorphism of the FcRn gene was found using DNAMAN software (version 5.2.10, Lyn-non Biosoft, Canada). Then all 296 samples from the three pig populations were genotyped by directly sequencing of PCR products.

\section{Association analysis}

In the end, we performed an association analysis of between genotypes of the SNP and serum CSFV antibody level by Statistical Analysis System (SAS) software (version 9.13), based on the following mixed model:

$$
\mathrm{y}=X \beta+Z b+e
$$

Where $\mathrm{y}$ is the vector of CSFV antibody IgG level in serum analyzed, $X$ is the design matrix for fixed effects; $\beta$ is the vector of fixed effects parameter including breed, ELISA plate effect and genotype effect. $Z$ is the design matrix of random animal effects; $b$ is the mixed vector of random component including sires effect and dam effect within sires; and $e$ is the vector of residual effect.

\section{RESULTS AND DISCUSSION}

\section{Sequence analysis of porcine FcRn gene}

The porcine FcRn cDNA is 1,577 bp in length (GenBank Accession Number: AY135635) and contains a 1,077 bp open reading frame (ORF) encoding a 356-amino acid polypeptide. The $3^{\prime}$ end of the sequence contains a poly(A) stretch, preceded by a putative polyadenylation signal AATAAA (nucleotides 1523-1529). Blast analysis revealed that the mRNA sequence of the porcine FcRn gene has $79.4 \%, 66.3 \%$ and $83.9 \%$ nucleotide identity with the corresponding gene in human, mouse and cattle respectively. Comparison of predicted porcine FcRn amino acid 


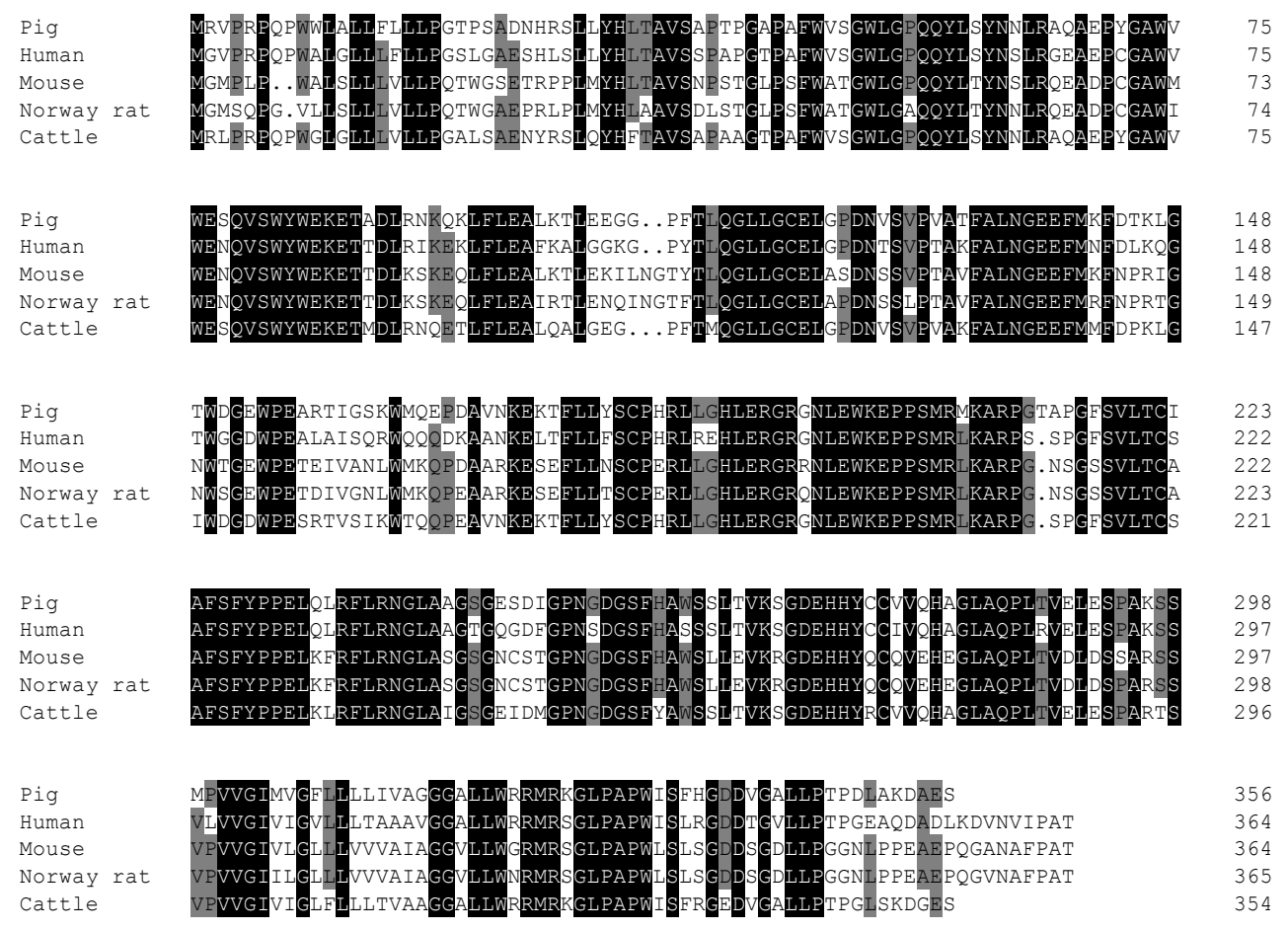

Figure 1. Alignment of predicted porcine FcRn amino acid sequence (Sus scrofa, NP_999362.2) with other species. The degree of homology is indicated by darker shading and justifying greater homology. Protein sequences are from GenBank (locus numbers: Human (Homo sapiens, NP_001129491.1), Mouse (Mus musculus, NP_034319.2), Norway Rat (Rattus norvegicus, NP_036986) and Cattle (Bos taurus).

sequence with that of human, mouse, rat and cattle indicated an identity of $77.1 \%, 66.3 \%, 64.2 \%$ and $83.9 \%$, respectively (Figure 1). The complete porcine FcRn genomic DNA sequence spans 8,900 bp (GenBank accession number: HQ026019) and it consists of 5 introns separating 6 exons. The intron/exon organization of porcine ( 5 introns and 6 exons) is identical with that of the human and mouse FcRn gene. These sequence characters will provide help in further understanding of the function of porcine FcRn in antiviral defense and immune regulation.

\section{Tissues expression of porcine FcRn gene}

To determine tissue distribution of the porcine IRF6 gene, real time quantitative PCR (Q-PCR) was applied to ten different tissue samples. Results showed that the mRNA of FcRn was expressed in all analysis tissues (Figure 2). The higher expression level was detected in liver, spleen, thymus and lymphoid. In addition, the relatively lower expression level was detected in non-immune tissues such as muscle and brain. There may be a potential relationship between higher expression level and immune response capacity, which should be further verified in a larger sample.

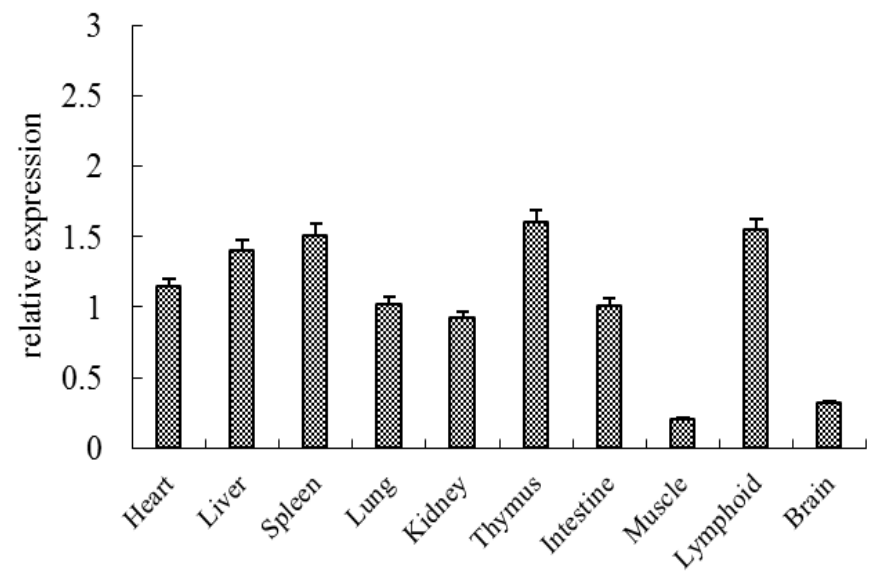

Figure 2. Expression of porcine FcRn mRNA detected by real time Q-PCR in different porcine tissues. The expression levels are represented relative to that for muscle and the values are means for three 35 days old piglets. 

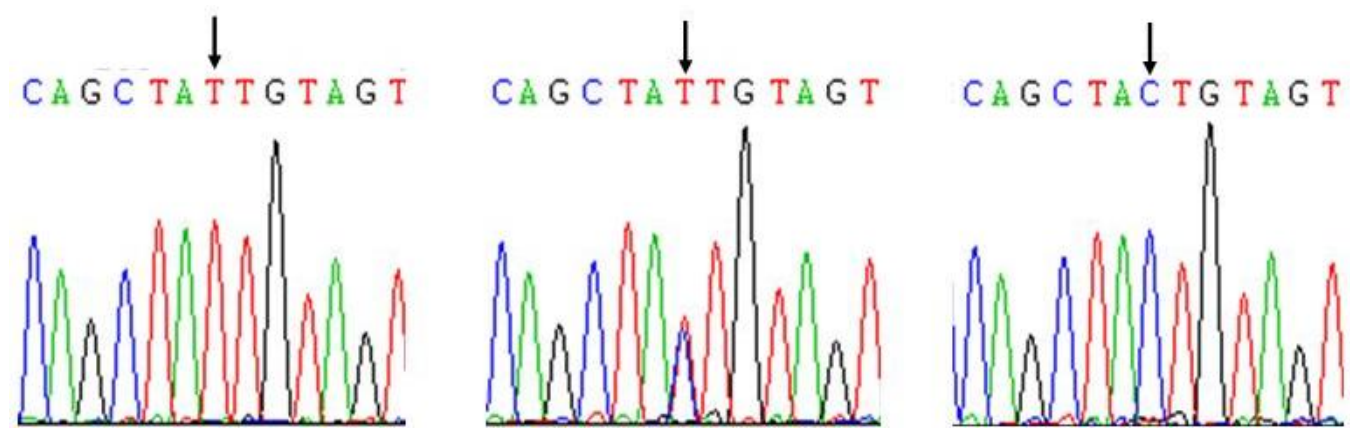

Figure 3. The sequencing maps of PCR fragments for exon6 region of porcine FcRn gene with the three genotypes of the SNP (HQ026019:g.8526 C>T) indicated by black arrows.

In some previous studies, FcRn mRNA has been detected in many tissues of adult rats, mice and humans, and FcRn is expressive in several adult tissues and in cell lines such as the vascular endothelium, professional APCs and the hepatocytes, which are consistent with our results in pigs (Israel et al., 1997; Simister et al., 1997; Brovak et al., 1998; Spiekermann et al., 2002; Shah et al., 2003; Ward et al., 2003; Mayer et al., 2004).

\section{Polymorphism detection and association analysis of} porcine FcRn gene

Comparison of sequences among three pig populations revealed one SNP (HQ026019:g.8526 C > T) in exon6 region of the porcine FcRn gene, and this SNP is a synonymous mutation (Figure 3). The genotypic and allele frequencies of this SNP in three pig populations are presented in Table 2. Results showed that genotype CC was dominant in Landrace and Large White populations, the allele $\mathrm{C}$ has higher frequencies than allele T. Genotype TT was only detected in Chinese indigenous breed Songliao Black population and genotype CT was a dominant genotype and allele $\mathrm{C}$ also had higher frequency in the Songliao Black population.
In the further association analysis, the SNP was highly significantly associated with CSFV antibody level (At d 20; At $d 35)$ in serum $(p=0.0008$ and $p=0.0001$ respectively) (Table 3). The results provided a potential relationship between FcRn gene and serum CSFV antibody level. In order to further understand the effective value of different genotypes acting on serum CSFV antibody level, we implemented multiple comparison tests for genotypes of the significant SNP. The results showed that genotypes TT, CT and $\mathrm{CC}$ showed highly significant differences in three pig populations $(p<0.01)$, and pigs with genotype TT have higher serum CSFV antibody levels (At d 20; At d 35) than pigs with genotypes CC and TC (Table 3).

CSFV can lead to classical swine fever (CSF), which is a highly contagious swine disease worldwide, and domestic pigs are the major natural host of this virus. CSFV could cause acute disease and mortality of fetuses, resulting in serious losses to pig industry (Dong and Chen, 2007). Thereby, improvement in the serum CSFV antibody level would help the host in defending against infection by CSF virus. Due to the important role of the FcRn gene in both perinatal IgG transport and IgG homeostatic functions, it can help in modulating the function and the serum level of

Table 2. Genotypic and allelic frequencies of the SNP (HQ026019:g.8526 C>T) of FcRn gene

\begin{tabular}{|c|c|c|c|c|c|c|}
\hline \multirow{2}{*}{ Breeds } & \multirow{2}{*}{ Number } & \multicolumn{3}{|c|}{ Genotypic frequencies } & \multicolumn{2}{|c|}{ Allelic frequencies } \\
\hline & & $\mathrm{CC}$ & $\mathrm{CT}$ & TT & $\mathrm{C}$ & $\mathrm{T}$ \\
\hline Landrace & 68 & 0.71 & 0.29 & 0 & 0.86 & 0.14 \\
\hline Large White & 163 & 0.51 & 0.49 & 0 & 0.76 & 0.24 \\
\hline Songliao Black & 65 & 0.34 & 0.42 & 0.25 & 0.55 & 0.46 \\
\hline
\end{tabular}

Table 3. Association analysis and multiple tests of the SNP (HQ026019:g.8526 C>T) of FcRn gene with serum CSFV antibody level in three pig populations

\begin{tabular}{|c|c|c|c|c|}
\hline \multirow{2}{*}{ Traits } & \multicolumn{3}{|c|}{ Polymorphism genotypes (LSM \pm SE) } & \multirow{2}{*}{ p-value } \\
\hline & $\mathrm{CC}(\mathrm{n}=152)$ & $\mathrm{CT}(\mathrm{n}=128)$ & TT $(n=16)$ & \\
\hline $\begin{array}{l}\text { CSFV antibody IgG } \\
(\text { At d 20) }\end{array}$ & $0.461 \pm 0.016^{\mathrm{A}}$ & $0.525 \pm 0.018^{\mathrm{A}}$ & $0.639 \pm 0.051^{\mathrm{B}}$ & $0.0008 * *$ \\
\hline $\begin{array}{l}\text { CSFV antibody IgG } \\
\text { (At d 35) }\end{array}$ & $0.297 \pm 0.025^{\mathrm{A}}$ & $0.388 \pm 0.016^{\mathrm{A}}$ & $0.531 \pm 0.044^{\mathrm{B}}$ & $0.0001 * *$ \\
\hline
\end{tabular}


IgG in the immune response._In this study, the detected SNP was not located in the promoter region and was not a functional mutation, however, synonymous SNPs have been reported that can affect protein expression by alteration or increase in the stability of the mRNA (Capon et al., 2004) and a "silent" polymorphism can change substrate specificity (Kimchi-Sarfaty et al., 2007). Our results showed that the SNP of FcRn gene had significant effects on serum CSFV antibody level in three pig populations and also indicated FcRn gene may be used as a genetic marker in pig disease resistance breeding.

Genetic background is one of the important factors that influence the immune capacity. In the multiple comparison tests for the SNP genotypes, genotype TT showed higher effective values than other genotypes in the serum IgG level, and it was the only detected in Chinese indigenous breed Songliao Black pig. These are interesting and can be used in the future for exploring the differences in the resistance to CSF between the Chinese indigenous pig breed and other Western commercial pig breeds. Since the number of pigs analyzed in our study was limited, therefore, further investigations are needed to confirm the relationship between the SNP with serum antibody level among other pig populations.

In summary, an 8,900 bp genomic organization with six exons and five introns of the FcRn gene was identified. The results of mRNA expression revealed that the porcine FcRn gene was widely expressed in ten analyzed tissues. One significant SNP (HQ026019:g.8526 C>T) in exon6 region of FcRn gene was also detected and association analysis results revealed that the SNP was highly significantly associated with serum anti-CSFV antibody level in three pig populations. The results indicated that FcRn gene should be regarded as a genetic marker with effects on serum antiCSFV antibody level in pig disease resistance breeding programmes.

\section{ACKNOWLEDGEMENTS}

This work is supported by the National Major Special Project of China on New Varieties Cultivation for Transgenic Organisms (Grand No. 2009ZX08009-146B) and China Postdoctoral Science Foundation Funded Project (Grand No. 2011M500455).

\section{REFERENCES}

Borvak, J., J. Richardson, C. Medesan, F. Antohe, C. Radu, M Simionescu, V. Ghetie and E. S. Ward. 1998. Functional expression of the MHC class I-related receptor, FcRn, in endothelial cells of mice. Int. Immunol. 10:1289-1298.

Brambell, F. 1966. The transmission of immunity from mother to young and the catabolism of immunoglobulins. The Lancet 2 : 1087-1093.
Capon, F., M. H. Allen, M. Ameen, A. D. Burden, D. Tillman, J. N. Barker and R. C. Trembath. 2004. A synonymous SNP of the corneodesmosin gene leads to increased mRNA stability and demonstrates association with psoriasis across diverse ethnic groups. Hum. Mol. Genet. 13:2361-2368.

Dong, X. N. and Y. H. Chen. 2007. Marker vaccine strategies and candidate CSFV marker vaccines. Vaccine 25:205-230.

Hinton, P. R., M. G. Johlfs, J. M. Xiong, K. Hanestad, K. C. Ong, C. Bullock, S. Keller, M. T. Tang, J. Y. Tso and M. Vásquez. 2004. Engineered human IgG antibodies with longer serum half-lives in primates. J. Biol. Chem. 279:6213-6216.

Hinton, P. R., J. M. Xiong, M .G. Johlfs, M. T. Tang, S. Keller and N. Tsurushita. 2006. An engineered human IgG1 antibody with longer serum half-life. J. Immunol. 176:346-356.

Israel, E., S. Taylor, Z. Wu, E. Mizoguchi, R. Blumberg, A. Bhan and N. Simister. 1997. Expression of the neonatal Fc receptor, FcRn, on human intestinal epithelial cells. Immunology 92: 69-74.

Jones, E. A. and T. A. Waldmann. 1972. The mechanism of intestinal uptake and transcellular transport of $\mathrm{IgG}$ in the neonatal rat. J. Clin. Invest. 51:2916-2927.

Kamei, D. T., B. J. Lao, M. S. Ricci, R. Deshpande, H. Xu, B. Tidor and D. A. Lauffenburger. 2005. Quantitative methods for developing $\mathrm{Fc}$ mutants with extended half-lives. Biotechnol. Bioeng. 92:748-760.

Kimchi-Sarfaty, C., J. M. Oh, I. W. Kim, Z. E. Sauna, A. M. Calcagno, S. V. Ambudkar and M. M. Gottesman. 2007. A" silent" polymorphism in the MDR1 gene changes substrate specificity. Science 315:525-528.

Mayer, B., Z. Kis, G. Kajan, L. V. Frenyo, L. Hammarstrom and I. Kacskovics. 2004. The neonatal $\mathrm{Fc}$ receptor (FcRn) is expressed in the bovine lung. Vet. Immunol. Immunopathol. 98:85-89.

McCarthy, K. M., Y. Yoong and N. E. Simister. 2000. Bidirectional transcytosis of IgG by the rat neonatal $\mathrm{Fc}$ receptor expressed in a rat kidney cell line: a system to study protein transport across epithelia. J. Cell Sci. 113:1277-1285.

Morphis, L. G. and D. Gitlin. 1970. Maturation of the maternofoetal transport system for human $\gamma$-globulin in the mouse. Nature 228:573.

Petkova, S. B., S. Akilesh, T. J. Sproule, G. J. Christianson, H. Al. Khabbaz, A. C. Brown, L. G. Presta, Y. G. Meng and D. C. Roopenian. 2006. Enhanced half-life of genetically engineered human IgG1 antibodies in a humanized FcRn mouse model: potential application in humorally mediated autoimmune disease. Int. Immunol. 18:1759-1769.

Praetor, A., I. Ellinger and W. Hunziker. 1999. Intracellular traffic of the MHC class I-like IgG Fc receptor, FcRn, expressed in epithelial MDCK cells. J. Cell Sci. 112:2291-2299.

Raghavan, M. and P. J. Bjorkman. 1996. Fc receptors and their interactions with immunoglobulins. Annu. Rev. Cell Dev. Biol. 12:181-220.

Roberts, D. M., M. Guenthert and R. Rodewald. 1990. Isolation and characterization of the Fc receptor from the fetal yolk sac of the rat. J. Cell Biol. 111:1867-1876.

Roopenian, D. C. and S. Akilesh. 2007. FcRn: the neonatal Fc receptor comes of age. Nat. Rev. Immunol. 7:715-725.

Roopenian, D. C., G. J. Christianson, T. J. Sproule, A. C. Brown, S. Akilesh, N. Jung, S. Petkova, L. Avanessian, E. Y. Choi and D. 
J. Shaffer. 2003. The MHC class I-like IgG receptor controls perinatal IgG transport, IgG homeostasis, and fate of IgG-Fccoupled drugs. J. Immunol. 170:3528-3533.

Sambrook, J., E. F. Fritsch and T. Maniatis. 1989. Molecular cloning: a laboratory manual, 2nd edn. Cold Spring Harbor Laboratory Press, New York, USA.

Shah, U., B. L. Dickinson, R. S. Blumberg, N. E. Simister, W. I. Lencer and W. A. Walker. 2003. Distribution of the IgG Fc receptor, FcRn, in the human fetal intestine. Pediatr. Res. 53: 295-301.

Shields, R. L., A. K. Namenuk, K. Hong, Y. G. Meng, J. Rae, J. Briggs, D. Xie, J. Lai, A. Stadlen and B. Li. 2001. High resolution mapping of the binding site on human IgG1 for Fc $\gamma$ RI, Fc $\gamma$ RII, Fc $\gamma$ RIII, and FcRn and design of IgG1 variants with improved binding to the Fc $\gamma$ R. J. Biol. Chem. 276:65916604.
Simister, N., I. E. Jacobowitz, J. Ahouse and C. Story. 1997. New functions of the MHC class I-related Fc receptor, FcRn. Biochem. Soc. Trans. 25:481-486.

Simister, N. E. and K. E. Mostov. 1989. An Fc receptor structurally related to MHC class I antigens. Nature 337:184187.

Spiekermann, G. M., P. W. Finn, E. S. Ward, J. Dumont, B. L. Dickinson, R. S. Blumberg and W. I. Lencer. 2002. Receptormediated immunoglobulin $\mathrm{G}$ transport across mucosal barriers in adult life. J. Exp. Med. 196:303-310.

Vaccaro, C., J. Zhou, R. J. Ober and E. S. Ward. 2005. Engineering the $\mathrm{Fc}$ region of immunoglobulin $\mathrm{G}$ to modulate in vivo antibody levels. Nat. Biotechnol. 23:1283-1288.

Ward, E. S., J. Zhou, V. Ghetie and R. J. Ober. 2003. Evidence to support the cellular mechanism involved in serum IgG homeostasis in humans. Int. Immunol. 15:187-195. 